\title{
Phenotypic variation and developmental instability of life-history traits: a theory and a case study on within-population variation of resting eggs formation in Daphnia
}

\author{
Dmitry L. LAJUS* and Victor R. ALEKSEEV ${ }^{1)}$
}

Department of Ichthyology and Hydrobiology Faculty of Biology and Soil Sciences, St. Petersburg State University, 16 line V.O. 29, 199178, St. Petersburg, Russia

${ }^{1)}$ Zoological Institute of the Russian Academy of Sciences, University emb., 1, 199034, St. Petersburg, Russia

*e-mail corresponding author: dlajus@yahoo.com

\begin{abstract}
It is commonly accepted that within-population phenotypic variation is caused by genotypic and environmental heterogeneity. Non-genotypic variation is thought to result from diversity of environmental conditions alone. This however contradicts experimental data showing that even when both genetic and environmental sources of phenotypic variation are neglected, residual variation still exists. This residual phenotypic variation is caused by deviations of developmental trajectories from the target trajectory determined for particular genotype and environment, i.e. by developmental instability. This variation is well-known for morphological traits where it is measured most often by fluctuating asymmetry, i.e. random deviations from perfect symmetry, which can be easily separated from the other type of phenotypic variation. In morphological characters which do not possess symmetry or in non-morphological characters this variation cannot usually be separated from other type of non-genotypic variation, caused by environmental heterogeneity. Most researchers still believe that all non-genotypic variation, even under standardised experimental conditions, is caused by insufficient standardization of environment, rather than by other sources of phenotypic variation. When special efforts are undertaken to analyse variation caused by developmental instability, this variation contributes substantially to non-genotypic variation. To exemplify how variation caused by developmental instability can be separated from phenotypic plasticity we analysed phenotypic variation of resting egg formation in Daphnia pulicaria. The proportion of females carrying resting eggs has been shown to depend on the photoperiod of their mothers, revealing transgeneration effects (Alekseev \& Lampert 2001). Developmental instability manifests itself in differences between clonemates within an experimental vessel in a standardized environment. Some females produce resting eggs whereas others do not. Our estimations based on results obtained in experimental conditions and extrapolation to conditions in the wild showed that phenotypic plasticity, i.e. phenotypic response to changes of day duration in maternal environment (phenotypic plasticity) explains only 1-2\% of phenotypic variation whereas developmental instability explains approximately 98-99\% of phenotypic variance of this trait (i.e. producing or not producing resting eggs), if other factors causing phenotypic plasticity are absent. This example demonstrates a major role of developmental instability in variation of the trait under study. The contribution of developmental instability to phenotypic variation should be considered in studying evolutionary patterns of phenotypic traits.
\end{abstract}

Key words: developmental instability, life-history traits, maternal effect, phenotypic variation, resting egg formation

\section{INTRODUCTION}

It is commonly thought that phenotypic variation in the wild population of most bisexual species is determined by two factors. The first is the genotypic difference between the individuals. The second is caused by diversity of environmental conditions during the formation of the phenotypic trait and manifests itself as phenotypic plasticity. Therefore different environments may result in different phenotypes even if genotypes are the same.

Most studies focus on genotypic variation because this kind of variation provides the basis for population's adaptive response to change in environmental factors by means of selection. Much less attention is usually paid to the non-genotypic component. But some experiments have shown that even when both genetic and environmental causes of phenotypic variation have been accounted for, variation still exists. This was first reported by B. Astaurov (Astauroff 1930) who analysed variation between left and right halteres in inbred lines of Drosophila, variation in number of chaetae among homologous segments of polychetes and myriapods and variation between identical twins in a range of organisms. Therefore, Astaurov analysed situations where genotypic and environmental variation could be ignored. Astaurov concluded that any "...process of formation in an organism has some independent variation, which can be reduced neither to genotypic differences, nor to the direct effect of the environment. This stochastic variation is inherited in intrinsic conditions of the character formation and in small spontaneous alterations coming both from outside, from fluctuations of the environment, and inside, from the organic structure itself..." (Astaurov (1974), p. 103, translation from the later Russian version of Astaurov's original German version by Lajus \& Alekseev 2000).

Independently, and many years later, Gärtner (1990) worked with laboratory animals such as rats and mousses, attempting to remove genetic variation by in- 
breeding, and removing environmental variation by keeping them under standardized conditions. The author measured a suite of parameters including liver weight. After 30 years of experiments it appeared that $70-80 \%$ of total phenotypic variance could not be accounted for by either genotypic or environmental variation. The author decided that there is a third source of phenotypic variation which appeared as a result of developmental processes (see Graham et al. (2003) and Lajus et al. (2003) for more discussion). Contribution of this type of variation to total variation notably exceeded the contribution of variation induced by environmental diversity. The title of Gärtner's paper "A third component causing random variability beside environment and genotype. $A$ reason for the limited success of a 30 year long effort to standardize laboratory animals?" therefore sums up his view.

Despite this literature, most researchers, even when admitting developmental instability as a source of phenotypic variation, consider this to be a variation of environmental origin. Falconer and Mackay (1996 pp. 134135), in their "Introduction to quantitative genetics" write: "...Environmental variance, which by definition embraces all variation of non-genetic origin, can have a great variety of causes... Some ... may arise from 'developmental' variation: variation, that is, which cannot be attributed to external circumstances, but is attributed, in ignorance of its exact nature, to 'accidents' or 'errors' of development as a general cause". In contrast, we argue that phenotypic variation which results from developmental processes should be considered as independent source of phenotypic variation standing on equal footing with genotypic and environmental components (Lajus et al. 2003). This variation is caused by deviations of developmental trajectories from the target trajectory determined for particular genotype and environment, i.e. by developmental instability.

Variation caused by developmental instability is well-known for morphological traits and is manifested as fluctuating asymmetry, i.e. random deviations from perfect symmetry (Van Valen 1962). In this study, we consider what role variation caused by developmental instability plays in life-history traits and illustrate this with a case study on formation of resting eggs in Daphnia pulicaria (Cladocera, Crustacea).

\section{DEVELOPMENTAL INSTABILITY IN SYMMETRIC MORPHOLOGICAL TRAITS: FLUCTUATING ASYMMETRY}

Developmental instability is most often studied by analysis of fluctuating asymmetry, which is convenient for analysis because partitioning out different components of phenotypic variation does not require experiments. Contribution of fluctuating asymmetry to total phenotypic variance is rather high and varies in morphological characters usually range from 10 to $40 \%$ in morphometric and from $50 \%$ to $70 \%$ in meristic characters (Lajus et al. 2003). Developmental instability increases due to stresses, either genetic or environmental (Zakharov 1987; Møller \& Swaddle 1997; Polak 2003).

One cause of genetic effects on a population's level of developmental instability is alteration of co-adapted gene complexes. More heterozygous populations usually have lower fluctuating asymmetry (Leary et al. 1992; Blanco et al. 1990; Kozhara 1994), while heterozygotes can produce a greater variety of biochemical products and hence can canalize their development better under a wide range of environmental conditions (Lerner 1954). Inbreeding increases expression of deleterious recessive alleles, and hence often leads to increase in developmental instability (Leary et al. 1983; Bongers et al. 1997). Hybridization between genetically distinct populations may disrupt their development because allelic combination in the hybrids have not been subjected by natural selection (Graham \& Felley 1985). Also, directional selection results in appearance of new forms of organisms from initial one and hence, disrupts evolved co-adapted gene complexes. For instance, developmental instability is usually higher in domesticated animals than in their wild relatives (Zakharov 1987; Parsons 1990). Incorporation of mutant genes also can upset developmental stability (see reviews Zakharov 1987, Møller \& Swaddle 1997; Thornhill \& Møller 1997).

Potentially, any one environmental factor can disrupt developmental pathways and hence increase developmental instability. One of the most important factors is temperature (Leary et al. 1992; Ruban 1992; Campbell et al. 1998). In natural conditions, large changes of temperature regime, for instance, during El Nino, also can result in developmental instability in fish (Alados et al. 1993). In many studies it has been shown that pollution can cause developmental instability (Valentine \& Soule 1973; Valentine et al. 1973, Ames et al. 1979; Østbye et al. 1997). There are several examples of increase of fluctuating asymmetry in locations with elevated level of radiation (Zakharov \& Krysanov 1996). Developmental instability can also result from crowding (Wiener \& Rago 1987; Leary et al. 1991). Nutrition stress, together with suboptimal temperature, is a common combination of environmental stresses, resulting in developmental instability in fishes (Kirpichnikov 1981, 1987).

Developmental instability does not remain stable in disturbed populations and decreases from generation to generation due to re-coadaptation of gene complexes. For instance, fluctuating asymmetry in sternopleural bristle number of Drosophila melanogaster decreases by $18 \%$ in the first seven generations after applying stress (Blows \& Sokolowski 1995). Hybrids and haploid organisms sometimes do not exhibit increased asymmetry (Felley 1980; Clarke et al. 1992), possibly, also due to re-coadatpation processes. 
But not all authors agree with the utility of fluctuating asymmetry for stress assessment (Bjorsten et al. 2000a), see also comments on this paper by Møller (2000), Van Dongen \& Lens (2000) and the reply by Bjorsten et al.(2000b)). For contemporary reviews of the problem, see Lens et al. (2002), Hoffman \& Woods (2003), Zakharov (2003) and Leung et al. (2003).

Usually, fluctuating asymmetry is measured on bilateral traits, i.e. using deviations from left-right or mirror symmetry. But it also can be analysed for other types of symmetry such as radial or translational (Graham et al. 1993; Tan-Kristanto et al. 2003). Multiple symmetrical structures are developed based on the same genotype under the same environmental conditions and therefore allow us to measure developmental instability.

Developmental instability represents the random or stochastic component of phenotypic variation. However, mechanisms of its regulation remain poorly known (Klingenberg 2003). Graham et al. (2003) consider that developmental instability has a complex nature with feedback interaction between involved structures and consists of different components.

\section{DEVELOPMENTAL INSTABILITY: MORE THAN FLUCTUATING ASYMMETRY}

Developmental instability can manifest itself not only as a difference between symmetric structures within a single individual. It can result also in differences between individuals when genotypic variation and environmental heterogeneity are negligible. For instance, when one compares twins, or clones cultivated under standard conditions, among-individual differences are mostly caused by developmental instability (Astauroff 1930). One can easily imagine, and even create, a situation where genotypic and environmental variations are nil, but one cannot create a situation where variation caused by developmental instability is nil (Lajus et al. 2003).

Experimental evidence of developmental instability other than fluctuating asymmetry are not frequent because researchers usually do not pay much attention to non-genotypic variation, which is considered to be caused by environmental heterogeneity alone. Indeed, even under standardized experimental conditions it is very difficult to prove that variation induced by environmental heterogeneity is negligible. Because of that, many researchers believe that non-genotypic variation, even in standardised experimental conditions, results from non-sufficient standardization of environment rather than from other sources of phenotypic variation.

A direct effect of environmental factors on phenotype, i.e. phenotypic plasticity, is usually assessed by comparison of groups of genetically similar organisms which are subjected to different environmental conditions. In this case, among-group variation is interpreted as resulting from the controlled environmental factor and within-group variation, which is often quite high, as resulting from non-controlled environmental heterogeneity. But we suppose that within-group variation is mostly caused by developmental instability.

In addition to papers by Astaurov (Astauroff 1930) and Gärtner (1990) considered above, there is further evidence of variation, caused neither genotypic or environmental heterogeneity. Experiments on repeatability of behavioural response (reaction of opening and closing of shell as a response to changes of salinity) showed that about $30 \%$ of within-population variation is caused by within-individual variation, i.e. coming not from genotypic or environmental heterogeneity. This percentage increases up to $50 \%$ when water temperature quickly changes from $12{ }^{\circ} \mathrm{C}$ to which animals were acclimated, to $20{ }^{\circ} \mathrm{C}$ (calculations are based on data from Lajus \& Sukhotin (1998) and Sukhotin et al. (2003)). Thus variation of behavioural response shows similar patterns to those typical for variation caused by instability, i.e. increase under unfavourable or novel conditions. Sources of such variation, however, are better attributed to behavioural or physiological instability rather to developmental instability. We suppose that they may be quite similar in their nature.

Another interesting observation is not based on direct experiments. S. Davidenkov, who during many years studied appearance of different diseases, mostly epilepsy, wrote that if one assumes that variation of some heritable characters related to the disease, depends only on environmental heterogeneity, it is very difficult to understand why magnitude of this variation is so similar under conditions with considerably different magnitude of environmental heterogeneity (Astaurov 1978). Therefore absence of relationship between environmental heterogeneity and magnitude of phenotypic variation presents evidence of additional sources of phenotypic variation.

If phenotypic non-genotypic variation would depend only on environmental diversity, we should expect greater difference in magnitude of variation in different situations. In other words, if all non-genotypic variation would caused by environmental diversity alone, we should observe close relationship between extent of environmental diversity and magnitude of non-genotypic variation.

\section{A CASE STUDY: DEVELOPMENTAL INSTABILITY AND EFFECTS OF DAY DURATION ON RESTING EGG FORMATION IN DAPHNIA PULICARIA}

Which data may shade light on the role of developmental instability in traits related to diapause? Our case study is based on experiments on phenotypic variation in resting egg formation and its dependence on day length of mothers environment in Daphnia (Alekseev \& Lampert 2001). Decrease of day length in the mother's environment results in increase of resting egg production in offspring. All experiments were performed on a 
single clone of Daphnia pulicaria, so excluding genotypic variation, and under standardised environment that excludes within-vessel environmental heterogeneity. Female offspring carrying resting eggs are very easily distinguishable from those without resting eggs, so preventing measurement error (mistakes in differentiation of two kinds of females), which always should be taken into account in studies of developmental instability (Palmer 1994; Palmer \& Strobeck 2003).

Phenotypic plasticity caused by heterogeneity of environmental conditions, indicates a phenotypic response to changes in day length: a six-hours decrease in day length from 16 to $10 \mathrm{~h}$ induces a statistically significant increase in production of resting eggs by $27 \%$ or $39 \%$ of long- and short-day offspring respectively (Alekseev \& Lampert 2001, Table. 1).

Developmental instability is shown in differences between clone-mates within an experimental vessel; some female offspring under a standardized environment produce resting eggs whereas others do not. It is possible, theoretically, that these among-individual differences may be caused by heterogeneity of the environment within a vessel, and thus reflect phenotypic plasticity. This argument is very difficult or even impossible to verify experimentally. Logical analysis shows however that such explanation is highly improbable. The most important factors which are known to effect resting egg formation in Daphnia such as day length and food concentration in both mothers and offspring were strictly controlled in this study. Only a 6hours difference in day duration and a 5-fold difference in food concentration resulted in statistically detectable phenotypic response, and cannot be therefore considered as major factors causing phenotypic variation within a vessel. Therefore, to explain such variation by environmental heterogeneity we would need to assume that a unknown factor caused the effect observed. It is clearly to attribute within-vessel variation to developmental instability.

What results would have been achieved in the absence of developmental instability, i.e. if all individuals had the same value of the phenotypic trait? Here, above the threshold value of the environmental factor (Fig. 1a) all the individuals would not produce resting eggs, and below the threshold would produce, i.e. manifesting an ideal phenotypic plasticity. Developmental instability confounds response to environmental changes and hence decreases phenotypic plasticity (Fig. 1b).

The threshold value can be approximately assessed based on our data. The value of the factor where $50 \%$ of individuals produce resting eggs can be estimated using extrapolation of available data. For the extrapolation we used a linear regression analysis for simplicity. An sigmoidal model may be more realistic, but we do not require very accurate estimates because our purpose is simply to demonstrate a general principle of such analyses. Calculated values for day lengths are shown with open circles and those for the threshold value of the factor, where $50 \%$ of individuals produce resting eggs, are shown with solid circles (Fig. 2a). That value is 10.4 $\mathrm{h}$ for short-day offspring and $7.3 \mathrm{~h}$ for long-day offspring. When developmental instability is absent, the line is step-like (the step coincides with threshold value) and a response to environmental changes is instantaneous (Fig. 2b). The weaker the slope in figure $2 a$, the higher contribution of developmental instability. When phenotypic plasticity is absent, i.e. all the variation results from developmental instability, the line is parallel to the axis $\mathrm{X}$. In this case a response to environmental change can not take place.

Available data allow quantitative, though very approximate, assessment of the contribution of developmental instability to among-individual variation in resting egg production under natural conditions. In experimental conditions we have data on phenotypic response caused by change of day duration of mothers to $6 \mathrm{~h}$. In natural conditions, such a large difference between animals in terms of day duration of their mothers never occurs. Given that the life span of Daphnia is about one week, differences in day duration experiencing by animals which were born at the beginning compared to the end of week are about $15 \mathrm{~min}$ (calculated for spring or autumn season in moderate latitudes). Therefore, if one assumes a negative relationship between the percentage of females carrying resting eggs and day length (as appeared in experiment), the phenotypic response to changes of light regime in the wild would be $1.1 \%$ and $1.6 \%$ for short- and long day offspring respectively. These figures indicate a shift in probability of resting egg production of a single individual induced by shift of mothers day length over one week. Therefore, the remainder of the phenotypic variance, i.e. $98-99 \%$, should be attributed to developmental instability. This is true if variation of other factors, effecting resting egg formation such as food concentration, temperature, is absent. Even if some of these factors occur, they probably contribute of about the same magnitude of variation as photoperiod, i.e. in any case contribution of developmental instability is very high in comparison with phenotypic plasticity.

\section{WHY IT IS IMPORTANT TO DIFFERENTIATE VARIATION CAUSED BY DEVELOPMENTAL INSTABILITY FROM PHENOTYPIC PLASTICITY?}

Knowledge about the contribution of different components to phenotypic variance helps us better understand a phenotypic trait's evolutionary patterns. Traits with a higher contribution of variation caused by environmental heterogeneity will show higher phenotypic plasticity. If most non-genotypic variation is caused by phenotypic plasticity, even weak changes in environmental conditions will cause a phenotypic response. And vice versa, in characters with high contribution of developmental instability, phenotypic plasticity will be low. 
a

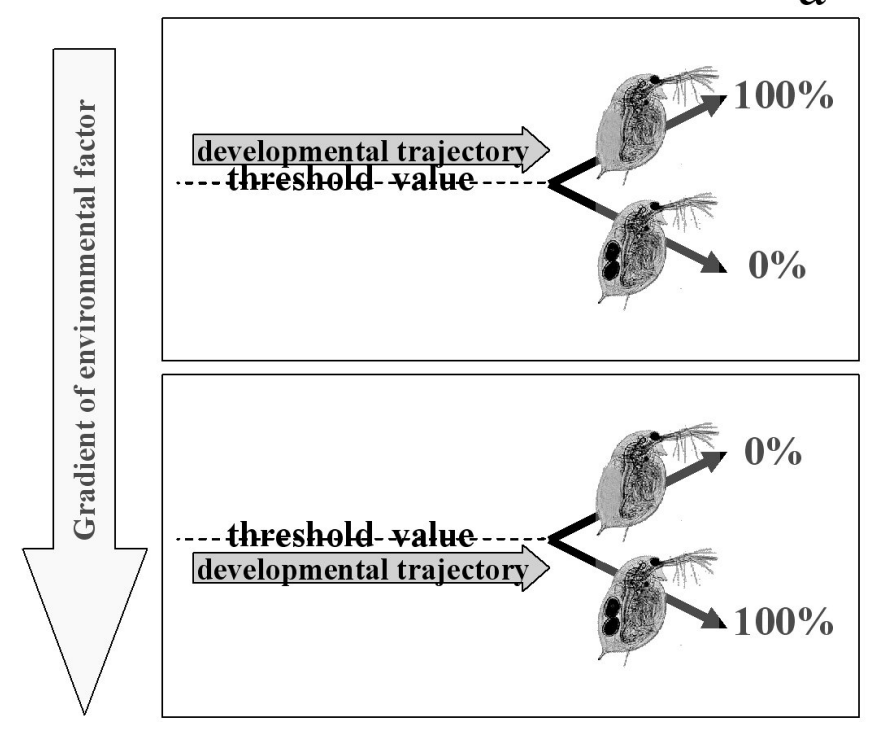

b

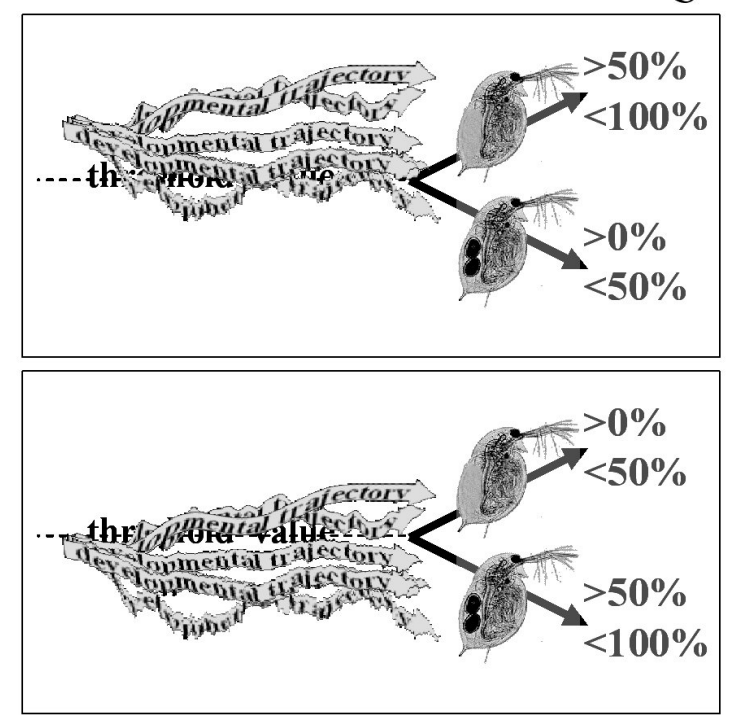

Fig. 1. Changes in resting egg formation in Daphnia depending on an environmental factor (scheme): in absence (a) and in presence (b) of developmental instability.
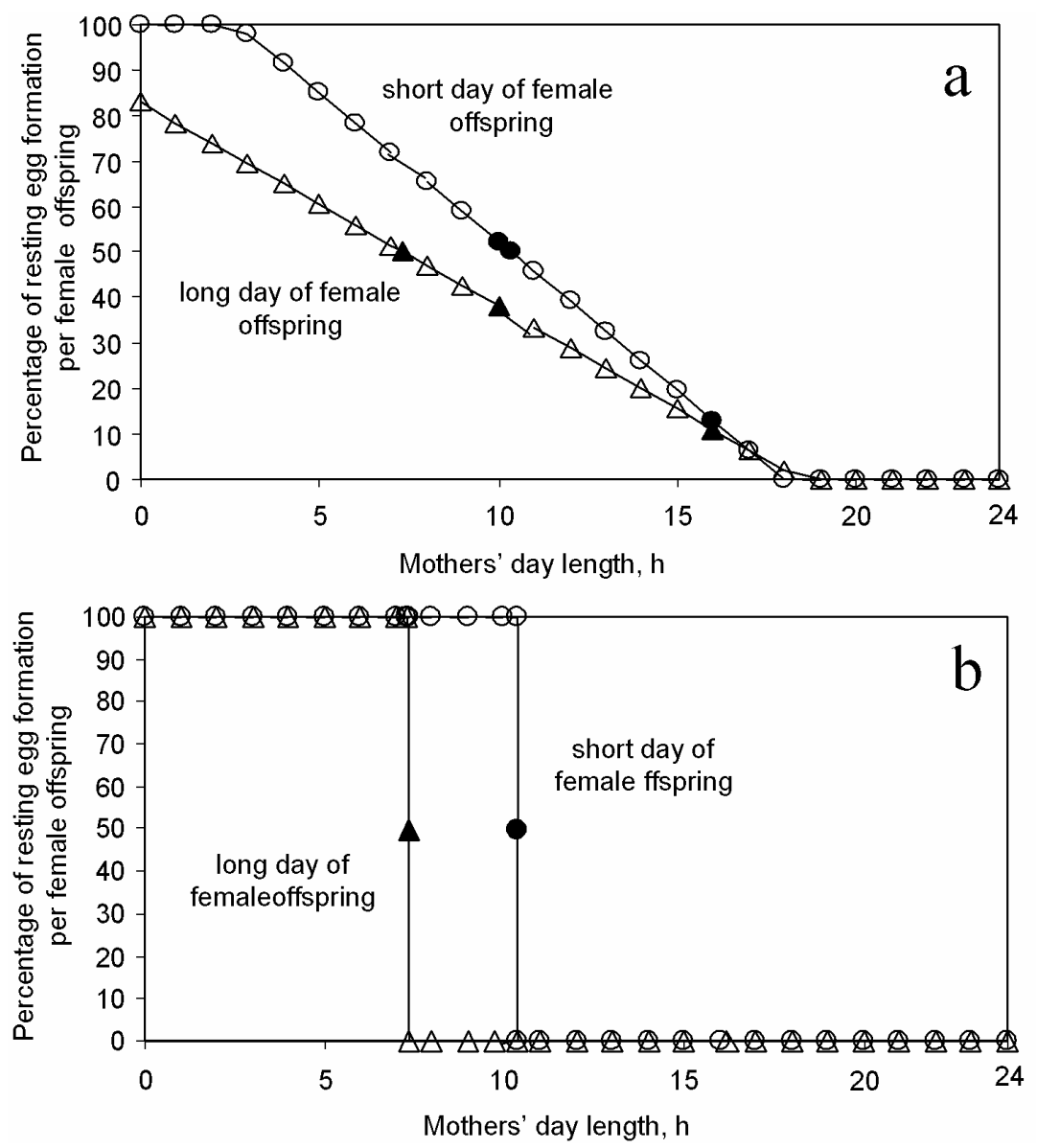

Fig. 2. Effect of day length of mothers on production of resting eggs by offspring in different day lengths based on experimental data (Alekseev \& Lampert 2001) (a), and a model which suggests absence of variation caused by developmental instability (b). Grey circles and triangles - empirical data. Other figures are in accordance with a linear model of the relationship between day length and percentage of offspring females with resting eggs; solid symbols mark values of $50 \%$ of resting eggs per female. 
For instance, in our case study the contribution of developmental instability was high, which would make nearly impossible to detect a phenotypic response with a shift of day duration of $15 \mathrm{~min}$. Only a shift of several hours causes a statistically detectable response. However, even such a small response may have important evolutionary consequences. Assuming that developmental instability in life-history traits, like in morphological traits, is quite variable depending on environmental and genetic factors, we may suppose that it causes quite high variation in phenotypic plasticity.

Also, developmental instability may affect heritability of characters and therefore their response to selection. As heritability represents the contribution of genotypic variation to total phenotypic variance, changes in developmental instability, given that its contribution may be high, can considerably change heritability. This effect should be stronger under changing and novel conditions, when developmental instability usually increases. Figuratively speaking, the population preserves itself against fast potential changes of its genome under changing environment.

On the other hand, when the magnitude of genetic variation is insufficient to create a diversity of phenotypes which can be exposed to selection, developmental instability can enrich the evolutionary potential of a population. Developmental fluctuations will contribute to the appearance of extreme phenotypes by exposing them to selection, thus affecting frequencies of the corresponding genotypes (and contributing to lower phenotypic variation). Without developmental instability, phenotypes would be more homogenous, which could result, via selection, in more homogenous genetic composition of the population. In such a way, the genetic structure of a population may change even under constant environmental conditions through accumulation of genetic variation (Lajus et al. 2003). Such "development" of the population gene pool is similar to the effect of extreme environments when they make specific genes, or gene combinations, available to selection (Waddington 1957).

Knowledge about the contribution of variation resulting from developmental instability to phenotypic variance may also provide valuable information for planning experiments. In some cases, for instance when analysing genotypic variation, it is important to reduce non-genotypic variation. Standardisation of environmental conditions is common way to approach this, but it is difficult. Perfect standardization, however, is important only in the case where the contribution of phenotypic plasticity in trait's variation is high. Only in this case, standardisation of environmental conditions will be effective in minimising phenotypic variation. If the contribution of environmental heterogeneity is low, i.e. contribution of developmental instability is high, such standardisation will have only very limited effect, because the efforts will only deal with the very low pro- portion of total variance. Probably, it is much more important in most cases to create the conditions where developmental instability is minimal, i.e. to conduct experiments under constant conditions which are close to optimal, rather to try approach high standardization.

\section{CONCLUSIONS}

Each individual in the population deviates from the population mean. Causes of deviation are not always known for particular individuals but can be statistically partitioned out using samples of individuals. Departures from means are caused by factors of different natures. Genotypic variation allows the population to adapt to changes in environment over generations via selection of the most fit individuals. Phenotypic plasticity is a response to environmental changes within one generation, and also contributes to a population's adaptation to the environment. There is also another source of variation which cannot be considered as adaptive variation, since it is caused by developmental instability, representing deviation from a target phenotype for a given genotype and environment. It likely contributes greatly to phenotypic variance of life-history traits, although its role has not been considered to date. Developmental instability represents the random or stochastic component of phenotypic variance, which confounds measurements of other sources of phenotypic variation. Even if genotypic variation and phenotypic plasticity would be constant, changes in developmental instability will change contribution of these sources of phenotypic variation in total variance. The higher the contribution of developmental instability the more pronounced such an effect is. Given that available data reveal a high contribution of developmental instability in phenotypic variation, it likely plays an important role in evolution.

\section{ACKNOWLEDGMENTS}

We thank David Booth for valuable comments and improving English. The study was partly supported by from Russian Foundation for Basic Research, grants 0104-49074 and N 04-04-49121 RFBR.

\section{REFERENCES}

Alados, C.L., J. Escos \& J.M. Emlen. 1993. Developmental stability as an indicator of environmental stress in the $\mathrm{Pa}$ cific hake (Merluccius productus). Fish. Bull., 91: 587-593.

Alekseev, V.R., \& W. Lampert. 2001. Maternal control of resting-egg production in Daphnia. Nature, 414: 899-901.

Ames, L. J., J.D. Felley \& M.E. Smith. 1979. Amounts of asymmetry in centrarchid fish inhabiting heated and nonheated reservoirs. Trans. Am. Fish. Soc., 108: 485-489.

Astauroff, B.L. 1930. Analyse der erblichen Störungsfälle der bilateralen Symmetrie im Zusammenhang mit der selbstständigen Variabilität änlicher Strukturen. Zeitschrift für induktive Absammungs- und Vererbungslehre, 55 (3): $183-262$

Astaurov, BL. 1974. [Study of hereditary deviations from bilateral symmetry, associated with variation of metameric structures]. In: P.F. Rokitskii (Ed.) Nasledstvennost' $i$ raz- 
vitie. Moscow: Nauka Press: 54-109. Translation from German into Russian of the paper Astaurov (1930).

Astaurov, B.L. 1978. [On the results of my scientific activities in the field of genetics]. Istoriko-biologichaskie issledovaniia. M. Nauka Press, 6: 114 - 160. (In Russian).

Bjorksten, T.A., K. Fowler \& A. Pomiankowski. 2000a: What does sexual trait FA tell us about stress? Trends in Ecology and Evolution, 15: 163-166.

Bjorksten, T.A., K. Fowler \& A. Pomiankowski. 2000b: Untitled. Trends in Ecology and Evolution. 15: 331.

Blanco, G., J.A. Sanchez, E. Vazques, E. Garcia \& J. Rubio. 1984. Superior developmental stability of heterozygotes at enzyme loci in Salmo salar L. Aquaculture. 84: 199-209.

Blows, M.W. \& M.B. Sokolowski. 1995. The expression of additive and nonadditive genetic variation under stress. Genetics, 140: 1149-1159.

Bongers, A.B.J., M.Z. Ben-Ayed, Z.B. Doulabi, J. Komen \& C.J.J. Richter. 1997. Origin of variation in isogenic, dynogenetic, and androgenetic strains of common carp, Cyprinus carpio. J. Exper. Zool., 277: 72-79.

Campbell, W.B, J.M. Emlen \& W.K. Hershberger. 1998. Thermally induced chronic developmental stress in coho salmon: integrating measures of mortality, early growth, and developmental instability. Oikos, 81: 398-410.

Clarke, G.M., Oldroyd B.P. \& P. Hunt. 1992. The genetic basis of developmental stability in Apis mellifera: heterozigosity versus genic balance. Evolution, 46: 735-762.

Falconer, D.S, \& F.C. Mackay. 1996. Introduction to quantitative genetics. $4^{\text {th }}$ edition Longman, Essex, England: $464 \mathrm{pp}$.

Hoffman, A.A. \& R.E. Woods. 2003. Associating environmental stress with developmental stability: problems and patterns. In: M. Polak (Ed.), Developmental instability: causes and consequences. Oxford University Press. Oxford: 387-401.

Graham, J.H. \& J.D. Felley. 1985. Genomic coadaptation and developmental stability within introgressed populations of Enneacanhus gloriosus and E. obesus (Pisces: Centrarchidae). Evolution, 39: 104-114.

Graham, J.H., D.C. Freeman \& J.M. Emlen. 1993: Developmental stability: a sensitive indicator of populations under stress. In: W.G. Landis J.S. Hughes \& M.A. Lewis (Eds), Environmental toxicology and risk assessment. ASTM STP 1179. American Society for Testing and Materials, Philadelphia: $136-158$

Graham, J.H., J.M. Emlen, \& D.C. Freeman. 2003. Nonlinear dynamics and developmental instability. In: M. Polak (Ed.), Developmental instability: causes and consequences. Oxford University Press. Oxford: 35-50.

Graham, J.H., K. Shimitzu, J.M. Emlen, D.C. Freeman \& J. Merkel. 2003. Growth models and expected distribution of fluctuating asymmetry. Biological Journal of the Linnean Society, 80: 57-65.

Gärtner, K. 1990. A third component causing random variability beside environment and genotype. A reason for the limited success of a 30 year long effort to standardize laboratory animals? Laboratory animals, 24 (1): 71-77.

Kirpichnikov, V.S. 1981. Genetic Bases of Fish Selection. Springer-Verlag, Berlin, New York: $410 \mathrm{p}$.

Kirpichnikov V.S. 1987. Genetika i selektsiia ryb. Leningrad. Nauka Press (in Russian): 519 p.

Klingenberg, C.P. 2003. A developmental perspective on developmental instability: theory, models, and mechanisms. In: M. Polak (Ed.), Developmental instability: causes and consequences. Oxford University Press. Oxford: 14-34.

Kozhara, A.V. 1994. Phenotypic variance of bilateral characters as an indicator of genetic and environmental conditions in bream Abramis brama (L.) (Pisces, Cyprinidae) population. J. Appl. Ichthyol., 10: 167-181.

Lajus, D.L. \& V.R. Alekseev. 2000. Components of morphological variation in baikalian endemial cyclopid Acantho- cyclops signifer complex from different localities. Hydrobiologia, 417: 25-35

Lajus, D.L. \& A.A. Sukhotin. 1998. A new approach for the assessment of stochastic variation: analysis of behavioural response in blue mussel (Mytilus edulis L.). Helgoländer Meeresuntersuchungen, 52: 141-145.

Lajus, D.L., J.H. Graham \& A.V. Kozhara. 2003. Developmental instability and the stochastic component of total phenotypic variance. In: M. Polak (Ed.), Developmental instability: causes and consequences. Oxford University Press. Oxford: 343-363.

Leary, R.F, F.W. Allendorf \& K.L. Knudsen. 1983. Developmental stability and Enzyme heterozygosity in Rainbow Trout. Nature, 301: 71-72.

Leary, R.F, F.W. Allendorf \& K.L. Knudsen. 1991. Effects of rearing density on meristics and developmental stability of rainbow trout. Copeia, $: 44-49$.

Leary, R.F, F.W. Allendorf \& K.L. Knudsen. 1992. Genetic, environmental, and developmental causes of meristic variation in rainbow trout. Acta Zool. Fenn., 191: 79-95.

Lens, L., S. Van Dongen, S. Kark, \& E. Matthysen E. 2002: Fluctuating asymmetry as an indicator of fitness: can we bridge the gap between studies? Biol. Rev., 77: 27-38.

Lerner, I. M. 1954. Genetic Homeostasis. Oliver and Boyd, London: $134 \mathrm{p}$.

Leung, B., L. Knopper. \& Mineau P. 2003: A critical assesment of the utility of fluctuating asymmetry as a biomarker of anthropogenic stress. In: M. Polak (Ed.), Developmental instability: causes and consequences. Oxford University Press. Oxford: 415-426.

Møller, A.P. 2000: Symmetry, size and stress. Trends in Ecology and Evolution, 15: 330.

Møller, A.P. \& J.P. Swaddle. 1997. Asymmetry, developmental stability and evolution. Oxford: Oxford University Press: $292 \mathrm{p}$.

Østbye, K., S.A. Øxnevad \& L.A. Vøllestad. 1997. Developmental stability in perch (Perca fluviatilis) in acidic aluminium-rich lakes. Can. J. Zool., 75: 919-928.

Palmer, A.R. 1994. Fluctuating asymmetry analysis: In: T.A. Markow (Ed.), Developmental instability: its origins and evolutionary implications. Kluwer, Dortrecht: 335-364

Palmer, A. R. \& Strobeck C. 2003. Fluctuating asymmetry analysis revisited. In: M. Polak (Ed.), Developmental instability: causes and consequences. Oxford University Press. Oxford: 279-319.

Parsons, P.A. 1990. Fluctuating asymmetry: An epigenetic measure of stress. Biol. Rev., 65: 131-145.

Polak, M. (Ed.). 2003. Developmental instability: causes and consequences. Oxford University Press: $560 \mathrm{p}$.

Ruban, G. I. 1992. Plasticity of development in natural and experimental populations of Siberian sturgeon Acipenser baeri Brandt. Acta Zool. Fenn., 191: 43-46.

Tan-Kristanto, A., A. Hoffmann, R. Woods, P. Batterham, C. Cobbett \& C. Sinclair. 2003. Translational asymmetry as a sensitive indicator of cadmium stress in plants: a laboratory test with wild-type and mutant Arabidopsis thaliana. New Phytologist, 159 (2): 471-477.

Sukhotin, A.A., D.L. Lajus \& P.A. Lesin. 2003. Influence of age and size on activity and stress resistance in marine bivalve Mytilus edulis. J. Exper. Mar. Biol. Ecol., 284 (1/2): 129-144.

Thornhill, R. \& A. P. Møller. 1997. Developmental stability, disease and medicine. Biol. Rev., 72: 497-548.

Valentine D.W. \& M. Soulé. 1973. Effect of p,p'-DDT on developmental stability of pectoral fin rays in the grunion, Leuresthes tenius. Fish. Bull., 71: 921-926.

Valentine, D.W., M.E. Soulé \& P. Sammalow. 1973. Asymmetry analysis in fishes: a possible indicator of environmental stress. Fish. Bull., 71: 357-370.

Van Dongen, S. \& L. Lens. 2000: Symmetry, size and stress. Trends in Ecology and Evolution, 15:330. 
Waddington, C.H. 1957. The strategy of the Genes. London: $420 \mathrm{pp}$.

Wiener, J. G. \& P. J. Rago. 1987. A test of fluctuating asymmetry in bluegills (Lepomis macrochirus Rafinesque) as a measure of pH-related stress. Env. Poll., 44: 27-36.

Zakharov, V.M. 1987. Asymmetria zhivotnykh: populatsionnofenogeneticheskyii podkhod. Nauka Press, Moscow: 136 pp. (In Russian).
Zakharov V. M. \& E.Yu. Krysanov (Eds). 1996. Consequences of the Chernobyl Catastrophe: Environmental Health. Center for Russian Environmental Policy. Moscow Affiliate of the International Biotest Foundation, Moscow: $160 \mathrm{pp}$.

Zakharov, V.M. 2003. Linking developmental stability and environmental stress: a whole organism approach. In: M. Polak (Ed.), Developmental instability: causes and consequences. Oxford University Press. Oxford: 402-414. 